\title{
Eosinophil count at intensive care unit admission was not predictor of hospital mortality: results of a case control study
}

Emmanuel Jesús Escobar-Valdivia ${ }^{1}$, Julio Edgardo González-Aguirre ${ }^{2^{*}}$, Eunice Rebeca Carrillo-Cisneros ${ }^{1}$, Karla Carolina Guerra-Leza ${ }^{1}$ and Roberto Mercado-Longoría ${ }^{2}$

\begin{abstract}
Background: Predicting mortality in the intensive care unit (ICU) is one of the biggest challenges in critical care medicine. Several studies have linked the presence of eosinopenia with adverse outcomes in different populations.

Methods: We performed a case control study to determine whether the eosinophil count at ICU admission was a predictor of hospital mortality. We included data from patients 18 years or older admitted to the medical or surgical ICU in a university hospital in northern of Mexico. Medical records of 86 non-survivors (cases) and 99 discharged alive patients (controls) were randomly reviewed; clinical records of patients with an ICU stay of less than $24 \mathrm{~h}$ and those whose information was incomplete were excluded.

Results: Median of eosinophil count at ICU admission was 0.013 (interquartile range (IQR) 0.00 to 0.57 ) $\mathrm{K} / \mu \mathrm{L}$. There was no significant statistical difference in eosinophils at admission between survivors and non-survivors (0.014 [IQR 0.00 to 0.36 ] vs. 0.010 [IQR 0.00 to 0.57$] \mathrm{K} / \mu \mathrm{L}, P=0.35$ ). In the multivariate analysis, APACHE II score at ICU admission and discharge were the only mortality predictors. Survivors had a significantly greater increase in eosinophil count during the first 7 days of ICU stay (0.104 [IQR -0.64 to 0.41$]$ vs. 0.005 [IQR -1.79 to 0.43$] \mathrm{K} / \mu \mathrm{L}, P=0.004$ ).

Conclusions: In our study, eosinophil count at ICU admission was not associated with increased hospital mortality. The larger increase in number of eosinophils observed during the first week of ICU stay in surviving patients deserves to be investigated further.
\end{abstract}

Keywords: Critical care, Eosinophils, Hospital mortality

\section{Background}

Predicting mortality in the intensive care unit (ICU) is one of the biggest challenges in critical care medicine. A timely prognosis prediction is essential for proper decisionmaking. There are several scales to quantify severity of critical illness; most of them were validated in different populations, frequently in the context of clinical trials [1]. Although there is continuous progress in prediction model performance, their use in the individual patient should be considered with caution given its poor sensitivity $[2,3]$. In order to achieve a better estimate of mortality, scales

\footnotetext{
* Correspondence: jeglza111@gmail.com

Department of Pulmonary and Critical Care Medicine, "Dr. José E. González" University Hospital, Nuevo León Autonomous University, Av. Francisco I.

Madero1500, Suburb: Mitras Centro, Monterrey, NL 64460, Mexico

Full list of author information is available at the end of the article
}

based on biomarkers related to presence of oxidative stress or systemic inflammatory response have been developed; among the biomarkers most used in the ICU are Creactive protein, glucose, and lactate [4-7]. Several studies have linked the presence of eosinopenia with increased risk of death in patients with bacteremia [8], chronic obstructive pulmonary disease exacerbation [9], and in diverse populations admitted to the ICU [10-12]. The use of eosinopenia as a prognostic factor at ICU admission is attractive due to its availability, low cost, and minimum delay between taking blood samples and obtaining results. Its ease of application contrasts with complexity of various scales and algorithms currently used. While the scales with more clinical variables tend to show better performance compared to the simple ones [13], different biomarkers have shown robust prognostic power even when 
they are used individually $[5,6,14-16]$. The primary aim of this study was to determine whether the eosinophil count at ICU admission is a hospital mortality predictor.

\section{Methods}

\section{Patients and context}

We conducted a case control study using data from patients admitted to medical or surgical ICU from January to September 2013. Our hospital is a teaching tertiary center in northern Mexico; it has 23 intensive care beds: 13 for postoperative or trauma patients and 10 for patients with medical conditions. The study was approved by the ethics committee of Dr. José E. González University Hospital (registration number 14-004 NM).

\section{Data collection}

Medical records of non-survivors (cases) and discharged alive patients (controls) were randomly reviewed. All patients were 18 years or older. For both groups, we collected basic sociodemographic variables, diagnosis at ICU admission, daily eosinophil count during ICU stay, Acute Physiology and Chronic Health Evaluation II (APACHE II) score, Sequential Organ Failure Assessment (SOFA) scale and in-hospital death. For patients with more than one ICU admission or discharge, only the first event was included. We excluded patients who had incomplete clinical records or who were discharged to the general ward, transferred to another hospital or died within the first $24 \mathrm{~h}$ since ICU admission. Blood sampling was performed by the nursing staff, blood was collected through the proximal port of a central venous catheter and placed in tubes with ethylenediaminetetraacetic acid; the samples were processed in a CELL-DYN Ruby System (Abbott Diagnostics, Abbott Park, IL) in a central laboratory.

\section{Statistical analysis}

We estimated the sample size based in variable "eosinophil count at ICU admission" with the power.t.test function of the $\mathrm{R}$ commander ( $\mathrm{R}$ program, version 2.1.2). We calculated the standard deviation and corresponding mean for survivors and non-survivors to evaluate difference extent and get the size of the effect. The number needed to obtain a power of $80 \%$ and $95 \%$ confidence intervals was 77 patients in each group. We tested normal distribution with the Kolmogorov-Smirnov test. Data are shown as means and standard deviations for variables with normal distribution and as medians and interquartile ranges for non-normal variables. We used the $t$ test, the MannWhitney $U$-test, ANOVA or chi-square as indicated. We compared eosinophil count at admission between survivors and non-survivors and also compared eosinophil count at discharge and at third and seventh day in patients who remained in ICU at those times. We calculated the receiver operating characteristic (ROC) curve, area under the curve (AUC) and Youden index for eosinophil at ICU admission and compared it with AUC for APACHE II and SOFA. According with sample size, we tested the eight most significant variables in a multivariate analysis by the Cox proportional regression model; the multicollinearity between predictor variables was ruled out by introducing at multivariate analysis only those with Pearson correlation coefficient less than .80 . We defined a statistically significant difference as a $P$ value less than .05 . Analysis was performed using SPSS version 18.0 for Windows (SPSS Inc., Chicago, IL).

\section{Results}

During the study period, 735 patients were admitted at medical or surgical ICU and $179(24.3 \%)$ died. We included data of 185 patients, 99 (53.3\%) in the survivors group and 86 (46.5\%) in the non-survivors group. Clinical and demographic characteristics are shown in Table 1 . Mean age was $47 \pm 18$ years. Male sex was predominant. The most common cause of ICU admission was a medical disease (47 \%). Eighty-six patients had diagnostic criteria for sepsis, 27 (27.3 \%) in the survivors and 59 (68.6 \%) in the non-survivors group $(P<.001)$. Time and cause of death are shown in Table 2. Main mortality cause was septic shock in $53.5 \%$ of patients. Fifty-six (65.1\%) patients died from the disease that caused their admission.

Eosinophil count median at ICU admission was 0.013 (interquartile range (IQR) 0.00 to 0.57 ) $\mathrm{K} / \mu \mathrm{L}$. There was no statistically significant difference in admission eosinophils between survivor and non-survivor patients $(0.014$ [IQR 0.00 to 0.36 ] vs. 0.010 [IQR 0.00 to 0.57 ] $/ \mu \mathrm{L}, P=$ $0.35)$. In the 86 patients with sepsis, eosinophil count at admission was not different between survivors and nonsurvivors (0.013 [IQR 0.00 to 0.05 ] vs. 0.016 [IQR 0.00 to 0.06$] \mathrm{K} / \mu \mathrm{L}, P=0.44)$. Taking as a cutoff point, the traditional level of $0.40 \mathrm{~K} / \mu \mathrm{L}, 126(67.6 \%)$ patients presented eosinopenia at ICU admission, difference between groups was not significant (64 [64.6\%] vs. 61 [70.9\%], $P=0.36)$.

In univariate analysis the following factors were associated with hospital mortality: age, APACHE II and SOFA at ICU admission and discharge, sepsis, eosinophil count at ICU discharge, type 2 diabetes mellitus, chronic kidney disease, solid neoplasia, a medical diagnosis as admission cause, and discharge to the general ward during a night shift. Eosinophil count at $72 \mathrm{~h}$ showed borderline significance $(0.13$ [IQR 0.0 to 0.90 ] vs. 0.040 [0.0 to 0.76$] \mathrm{K} / \mu \mathrm{L}$, $P=.05)$. ICU stay was 2.5 days longer in the group of nonsurvivors (5 [IQR 1 to 28] vs. 7.5 [IQR 1 to 46 ] days, $P=$ $0.004)$. The total hospital stay was shorter in non-survivor group (18 [IQR 3 to 96 ] vs. 11.5 [2 to 56 ] days, $P=0.007$ ). Patients with elective surgery had a lower mortality (21 [21.2 \%] vs. 4 [4.7 \%], $P=0.001)$. Seventy-four $(74.7 \%)$ survivors and 45 (52.3\%) non-survivor patients remained 
Table 1 Clinical and demographic variables at ICU admission

\begin{tabular}{|c|c|c|c|c|}
\hline Variable & Total & Survivors & Non-survivors & $P$ value \\
\hline Patients & $185(100.0)$ & $99(53.5)$ & $86(46.5)$ & \\
\hline Age, years & $47(18.2)$ & $43(17.4)$ & $51(18.3)$ & 0.003 \\
\hline Men & $128(69.2)$ & $74(74.7)$ & $54(62.8)$ & 0.079 \\
\hline APACHE II, score & $16(1-37)$ & $12(1-30)$ & $21(9-37)$ & $<0.001$ \\
\hline SOFA, score & $6(0-20)$ & $5(0-14)$ & $9(2-20)$ & $<0.001$ \\
\hline Predicted mortality, \% & $25(4-85)$ & $15(4-75)$ & $40(9-85)$ & $<0.001$ \\
\hline \multicolumn{5}{|l|}{ Comorbidities } \\
\hline $\mathrm{DM} 2$ & $58(31.4)$ & $23(23.2)$ & $35(40.7)$ & 0.011 \\
\hline Ischemic cardiopathy & $24(13.0)$ & $12(12.1)$ & $12(14.0)$ & 0.711 \\
\hline Chronic nephropathy & $23(12.4)$ & $5(5.1)$ & $18(20.9)$ & 0.001 \\
\hline Chronic liver disease & $7(3.8)$ & $2(2.0)$ & $5(5.8)$ & 0.265 \\
\hline Chronic pneumopathy & $7(3.8)$ & $4(4.0)$ & $3(3.5)$ & 1.000 \\
\hline Blood neoplasia & $1(0.5)$ & $1(1.0)$ & $0(0.0)$ & 1.000 \\
\hline Solid neoplasia & $15(8.1)$ & $4(4.4)$ & $11(12.8)$ & 0.030 \\
\hline HIV infection & $5(2.7)$ & $1(1.0)$ & $4(4.7)$ & 0.285 \\
\hline \multicolumn{5}{|l|}{ ICU admission diagnosis } \\
\hline Medical & $87(47.0)$ & $37(37.4)$ & $50(58.1)$ & 0.005 \\
\hline Surgical, urgent & $40(21.6)$ & $19(19.2)$ & $21(24.4)$ & 0.389 \\
\hline Surgical, elective & $25(13.5)$ & $21(21.2)$ & $4(4.7)$ & 0.001 \\
\hline Trauma & $33(17.8)$ & $22(22.2)$ & $11(12.8)$ & 0.095 \\
\hline ICU admission eosinophils count, $\mathrm{K} / \mu \mathrm{L}$ & $0.013(0.0-0.578)$ & $0.014(0.0-0.363)$ & $0.010(0.0-0.578)$ & 0.355 \\
\hline Hospital stay, days & $14(2-96)$ & $18(3-96)$ & $11.5(2-56)$ & 0.007 \\
\hline ICU stay, days & $6(1-46)$ & $5(1-28)$ & $7.5(1-46)$ & 0.004 \\
\hline
\end{tabular}

Data are shown as number and percentage, mean and standard deviation or median and interquartile range as needed ICU intensive care unit, APACHE II acute physiology and chronic health evaluation II, SOFA sequential organ failure assessment score, DM2 type 2 diabetes mellitus, HIV human immunodeficiency virus

in ICU for a week or more; those who survived had a significantly greater increase in eosinophil count during the first 7 days of ICU stay (0.104 [IQR -0.64 to 0.41 ] vs. 0.005 [IQR -1.79 to 0.43$] \mathrm{K} / \mu \mathrm{L}, P=0.004$ ).

The AUC for eosinophil count at admission, APACHE II and SOFA was 0.53 (IQR 0.45 to 0.62 ), 0.83 (IQR 0.77 to 0.89 ), and 0.78 (IQR 0.71 to 0.84 ), respectively.
The results of the multivariate analysis are shown in Table 3. Only APACHE II score at admission and at discharge significantly predicted hospital mortality.

\section{Discussion}

Eosinophils are pleiotropic, multifunctional cells involved in the initiation and propagation of inflammatory response

Table 2 Time and death cause in non-survivors group

\begin{tabular}{|c|c|c|c|c|c|c|}
\hline Cause of death & Day 1 to 7 & Day 8 to 14 & Day 15 to 21 & Day 22 to 28 & Day 28 or later & Total \\
\hline Cancer & 1 & & & & & 1 \\
\hline Cardiogenic shock & 2 & 2 & & & 1 & 5 \\
\hline Hypovolemic shock & 2 & & & & & 2 \\
\hline Neurologic & 13 & & & & & 13 \\
\hline Pulmonary embolism & 1 & & & & & 1 \\
\hline Respiratory insufficiency & 5 & 5 & 1 & 2 & 3 & 16 \\
\hline Septic shock & 17 & 15 & 7 & 4 & 5 & 48 \\
\hline Total, n (\%) & $41(47.7)$ & $22(25.6)$ & $8(9.3)$ & $6(7.0)$ & $9(10.5)$ & $86(100.0)$ \\
\hline
\end{tabular}

Death causes are shown as number; total data are shown as number and percentage 
Table 3 Factors associated with hospital mortality, multivariate analysis

\begin{tabular}{llll}
\hline Variable & HR & $95 \% \mathrm{Cl}$ & $P$ value \\
\hline Age & 0.994 & $0.97-1.00$ & 0.407 \\
APACHE II at admission & 1.039 & $1.00-1.07$ & 0.048 \\
APACHE II at ICU discharge & 1.097 & $1.06-1.13$ & $<0.001$ \\
Hospital stay & 0.805 & $0.75-0.85$ & $<0.001$ \\
Eosinophils $<0.10 \mathrm{~K} / \mu \mathrm{L}$ at $72 \mathrm{~h}$ & 1.333 & $0.76-2.32$ & 0.312 \\
Eosinophils $<0.03 \mathrm{~K} / \mu \mathrm{L}$ at ICU discharge & 0.965 & $0.54-1.70$ & 0.903 \\
Discharge from ICU during night shift & 1.165 & $0.66-2.03$ & 0.591 \\
Medical diagnosis at ICU admission & 1.342 & $0.80-2.23$ & 0.259 \\
\hline
\end{tabular}

HR hazard ratio, $\mathrm{Cl}$ confidence interval, APACHE II acute physiology and chronic health evaluation II, SOFA sequential organ failure assessment score, ICU intensive care unit, DM2 type 2 diabetes mellitus

triggered by diverse stimulus [17]. Their life cycle is tightly regulated by granulocyte colony-stimulating factor, macrophages, IL-3, and IL-5; decrease in their concentration, as occurs during bacterial or fungal sepsis [18], causes eosinophil apoptosis after 48 to $72 \mathrm{~h}[17,19]$. In 1893, Zappert first described the reduction in eosinophil count related to acute infection [20]. It has been proposed that this decrease is due to at least three mechanisms: 1) peripheral sequestration in inflamed tissue, 2) eosinophils production inhibition, and 3) suppression of mature cell release from the bone marrow [10]. In animal model, there is an up to $80 \%$ reduction in eosinophil count within $6 \mathrm{~h}$ after the infective stimulus [21]. Several studies have proposed eosinopenia as a marker for infection [22-28]; in contrast, eosinophilia is infrequent during severe sepsis, and its presence even leads to questioning the infectious etiology of the systemic inflammatory response syndrome [29].

Eosinopenia is frequent and has been linked to mortality in different settings during critical illness; in our study, it was present in $67.5 \%$ of patients, an intermediate value compared to $46.5 \%$ and $86 \%$, reported by Ho et al. in critically ill patients with bacteremia $[7,28]$. We did not find an association between eosinophil count at ICU admission and hospital mortality, this contrast with that reported by other authors $[10,12,30]$. The retrospective design of our study, including an unselected population of critically ill patients and increased frequency of sepsis in the group of non-survivors, could explain this difference. We did not find a difference in eosinophil count at ICU admission between survivor and non-survivor patients with sepsis; the value of this analysis is limited due to a low number of included patients.

In univariate analysis, eosinophil count at $72 \mathrm{~h}$ showed borderline significance to predict hospital mortality $(0.13$ [IQR 0.0 to 0.90 ] vs. 0.040 [IQR 0.0 to 0.76 ] K/ $\mu \mathrm{L}, P=$ 0.05 ); we build ROC curve and identified $0.103 \mathrm{~K} / \mu \mathrm{L}$ as count with a greater discrimination power. However, at multivariate analysis this did not remain as an independent predictor of hospital mortality. Bass et al. found that circulating eosinophil number increases as early as $12 \mathrm{~h}$ after appropriate antibiotic treatment initiation [21]. Even though there is no evidence to support the $72 \mathrm{~h}$ as a specific point in time at which increase in eosinophil count relates to better outcomes, we arbitrarily defined a 72-h period based on theory that serial measurement of this biomarker could resemble the serial measurement of other markers along evolution of critical illness (e.g., procalcitonin); our results did not support this hypothesis.

A retrospective study of 1446 patients demonstrates that an eosinophil count $<0.01 \mathrm{~K} / \mu \mathrm{L}$ at ICU discharge is associated with an increased risk of readmission (HR 2.50 [95 \% CI 1.38 to 4.50], $P=0.002$ ) and hospital mortality (HR 2.65 [95 \% CI 1.77 to 3.98], $P=0.001$ ) [11]. Our ROC curve analysis placed that point in $0.031 \mathrm{k} / \mu \mathrm{L}$. Given that up to $10 \%$ of patients discharged from the ICU die before leaving the hospital [31], various scales have been developed to reduce the number of inadequate discharges from the ICU [32-34], but their use is frequently limited due to their complexity. In this regard, eosinopenia is an interesting marker: it may reflect a state of persistent inflammatory response, where the action of various cytokines avoids normalization of eosinophil count. However, in multivariate analysis of our data, eosinophils at ICU discharge were not significant predictors of hospital mortality; lack of significance at multivariate analysis could be due to the low number of patients since the sample size was not calculated for this outcome.

Consistent with the available literature $[8,10,30]$, we found that the inability to increase the eosinophil count was a predictor of mortality. In our study, survivors showed a 20-fold increase in the eosinophil count at the seventh day compared to non-survivors. The increase in eosinophil number during the first week of ICU stay in patients who survived is a valuable result given the biological context that relates their presence with the resolution of the inflammatory state $[7,21]$. This aspect becomes even more valuable given the easy access and low cost of blood cells count.

Our study has several limitations. First, its retrospective design involved a limited value in the quality of information; in addition, the background of comparative groups was different and potentially included several undetermined confounding factors. Second, we did not take into account the percentage of eosinophils with respect to total leukocyte count; this factor was related to an increase in predictive power, sensitivity, and AUC for mortality prediction in one study [12]. Third, patients were not stratified according to steroids or vasoactive amines use; these substances have been associated with eosinophils apoptosis [19]. Finally, the study was conducted at a single center. 


\section{Conclusions}

In this study, the eosinophil count at admission to the ICU was not associated with increased in hospital mortality. In our population, the APACHE II score at ICU admission and discharge remains as the best mortality predictors. The larger increase in eosinophil number during the first 7 days of ICU stay observed in survivor patients is a finding that deserves to be investigated in future studies.

\section{Abbreviations}

ICU: intensive care unit; IQR: interquartile range; APACHE II: Acute Physiology and Chronic Health Evaluation II; SOFA: Sequential Organ Failure Scale; ROC: receiver operating characteristic; AUC: area under curve; HR: hazard ratio.

\section{Competing interests}

The authors declare that they have no competing interests.

\section{Authors' contributions}

EE contributed with the original idea, protocol coordination, and statistical analysis; JG was responsible for the protocol direction and paper writing, also contributed with statistical analysis; EC and KG performed data acquisition; and RM contributed with the writing and review of the manuscript. All authors read and approved the final manuscript.

\section{Authors' information}

EE is a senior resident of Internal Medicine speciality. JG is a specialist in Internal, Pulmonary and Intensive Care Medicine; associated professor of Pulmonary and Critical Care Medicine department. EC is an intern of Internal Medicine department. KG is an intern of Internal Medicine department. RM is a specialist in Internal, Pulmonary and Intensive Care Medicine and chief of Pulmonary and Critical Care Medicine department.

\section{Acknowledgments}

We thank Roxana Saldaña-Vázquez MD and Carlos David Castillo-Hernández MD for their support in translation and review of this paper.

\section{Author details}

${ }^{1}$ Department of Internal Medicine, "Dr. José E. González" University Hospital, Nuevo León Autonomous University, Av. Francisco I. Madero1500, Suburb: Mitras Centro, Monterrey, NL 64460, Mexico. '2Department of Pulmonary and Critical Care Medicine, "Dr. José E. González" University Hospital, Nuevo León Autonomous University, Av. Francisco I. Madero1500, Suburb: Mitras Centro, Monterrey, NL 64460, Mexico.

\section{Received: 31 January 2015 Accepted: 21 May 2015}

Published online: 06 June 2015

\section{References}

1. Castella X, Artigas A, Bion J, Kari A. A comparison of severity of illness scoring systems for intensive care unit patients: results of a multicenter, multinational study: The European/North American Severity Study Group. Crit Care Med. 1995;23(8):1327-35.

2. Predicting outcome in ICU patients. 2nd European consensus conference in intensive care medicine. Intensive Care Med. 1994;20(5):390-7.

3. Huang YC, Chang KY, Lin SP, Chen K, Chan KH, Chang P. Development of a daily mortality probability prediction model from Intensive Care Unit patients using a discrete-time event history analysis. Comput Methods Programs Biomed. 2013;111(2):280-9. doi:10.1016/j.cmpb.2013.03.018.

4. Suberviola B, Castellanos-Ortega A, Ruiz Ruiz A, Lopez-Hoyos M, Santibanez M. Hospital mortality prognostication in sepsis using the new biomarkers sUPAR and proADM in a single determination on ICU admission. Intensive Care Med. 2013:39(11):1945-52. doi:10.1007/s00134-013-3056-z.

5. Badreldin AM, Doerr F, Elsobky S, Brehm BR, Abul-dahab M, Lehmann T, et al. Mortality prediction after cardiac surgery: blood lactate is indispensible. Thorac Cardiovasc Surg. 2013;61(8):708-17. doi:10.1055/s-0032-1324796.
6. Tang J, Gu Q. The association between early blood glucose fluctuation and prognosis in critically ill patients. Zhongguo Wei Zhong Bing Ji Jiu Yi Xue. 2012;24(1):50-3.

7. Ho KM, Dobb GJ, Lee KY, Towler SC, Webb SA. C-reactive protein concentration as a predictor of intensive care unit readmission: a nested case-control study. J Crit Care. 2006;21(3):259-65. doi:10.1016/j.jcrc.2006.01.005.

8. Terradas R, Grau S, Blanch J, Riu M, Saballs P, Castells X, et al. Eosinophil count and neutrophil-lymphocyte count ratio as prognostic markers in patients with bacteremia: a retrospective cohort study. PloS One. 2012;7(8):e42860. doi:10.1371/journal.pone.0042860.

9. Holland M, Alkhalil M, Chandromouli S, Janjua A, Babores M. Eosinopenia as a marker of mortality and length of stay in patients admitted with exacerbations of chronic obstructive pulmonary disease. Respirology. 2010;15(1):165-7. doi:10.1111/j.1440-1843.2009.01651.x.

10. Abidi K, Belayachi J, Derras Y, Khayari ME, Dendane T, Madani N, et al. Eosinopenia, an early marker of increased mortality in critically ill medical patients. Intensive Care Med. 2011;37(7):1136-42. doi:10.1007/s00134-011-2170-z.

11. Yip B, Ho KM. Eosinopenia as a predictor of unexpected re-admission and mortality after intensive care unit discharge. Anaesth Intensive Care. 2013;41(2):231-41.

12. Kim YH, Park HB, Kim MJ, Kim HS, Lee HS, Han YK, et al. Prognostic usefulness of eosinopenia in the pediatric intensive care unit. J Korean Med Sci. 2013;28(1):114-9. doi:10.3346/jkms.2013.28.1.114.

13. Keegan MT, Gajic O, Afessa B. Comparison of APACHE III, APACHE IV, SAPS 3 , and MPMOIII and influence of resuscitation status on model performance. Chest. 2012;142(4):851-8. doi:10.1378/chest.11-2164.

14. Lopez-Delgado JC, Rovira A, Esteve F, Rico N, Manez Mendiluce R, Ballus Noguera J, et al. Thrombocytopenia as a mortality risk factor in acute respiratory failure in H1N1 influenza. Swiss Med Wkly. 2013;143:w13788. doi:10.4414/smw.2013.13788.

15. Prisco L, Iscra F, Ganau M, Berlot G. Early predictive factors on mortality in head injured patients: a retrospective analysis of 112 traumatic brain injured patients. J Neurosurg Sci. 2012;56(2):131-6.

16. Bazick HS, Chang D, Mahadevappa K, Gibbons FK, Christopher KB. Red cell distribution width and all-cause mortality in critically ill patients. Crit Care Med. 2011;39(8):1913-21. doi:10.1097/CCM.0b013e31821b85c6.

17. Hogan SP, Rosenberg HF, Moqbel R, Phipps S, Foster PS, Lacy P, et al. Eosinophils: biological properties and role in health and disease. Clin Exp Allergy. 2008;38(5):709-50. doi:10.1111/j.1365-2222.2008.02958.x.

18. Cavaillon JM, Adib-Conquy M, Fitting C, Adrie C, Payen D. Cytokine cascade in sepsis. Scand J Infect Dis. 2003;35(9):535-44. doi:10.1080/ 00365540310015935.

19. IImarinen P, Moilanen E, Kankaanranta H. Regulation of spontaneous eosinophil apoptosis-a neglected area of importance. J Cell Death. 2014;7:1-9. doi:10.4137/JCD.S13588.

20. Zappert J. Ueber das Vorkommen der Eosinophilen Zellen in menschlichen Blute. Z Klin Med. 1893;23:227-308.

21. Bass DA. Behavior of eosinophil leukocytes in acute inflammation. II. Eosinophil dynamics during acute inflammation. J Clin Invest. 1975;56(4):870-9. doi:10.1172/JCl108166.

22. Shaaban H, Daniel S, Sison R, Slim J, Perez G. Eosinopenia: is it a good marker of sepsis in comparison to procalcitonin and C-reactive protein levels for patients admitted to a critical care unit in an urban hospital? J Crit Care. 2010;25(4):570-5. doi:10.1016/j.jcrc.2010.03.002.

23. Gil H, Magy N, Mauny F, Dupond JL. Value of eosinopenia in inflammatory disorders: an "old" marker revisited. Rev Med Interne. 2003;24(7):431-5.

24. Abidi K, Khoudri I, Belayachi J, Madani N, Zekraoui A, Zeggwagh AA, et al. Eosinopenia is a reliable marker of sepsis on admission to medical intensive care units. Crit Care. 2008;12(2):R59. doi:10.1186/cc6883.

25. Smithson A, Perello R, Nicolas JM. Is eosinopenia a reliable marker of sepsis? Crit Care. 2009;13(3):409. doi:10.1186/cc7877.

26. Lipkin WI. Eosinophil counts in bacteremia. Arch Intern Med. 1979;139(4):490-1.

27. Setterberg MJ, Newman W, Potti A, Smego Jr RA. Utility of eosinophil count as predictor of bacteremia. Clin Infect Dis. 2004;38(3):460-1. doi:10.1086/ 380846.

28. Wibrow BA, Ho KM, Flexman JP, Keil AD, Kohrs DL. Eosinopenia as a diagnostic marker of bloodstream infection in hospitalised paediatric and adult patients: a case-control study. Anaesth Intensive Care. 2011;39(2):224-30.

29. Pitman MC, Anstey NM, Davis JS. Eosinophils in severe sepsis in northern Australia: do the usual rules apply in the tropics? Crit Care Med. 2013;41(10):e286-8. doi:10.1097/CCM.0b013e3182923755. 
30. Merino CA, Martinez FT, Cardemil F, Rodriguez JR. Absolute eosinophils count as a marker of mortality in patients with severe sepsis and septic shock in an intensive care unit. J Crit Care. 2012;27(4):394-9. doi:10.1016/ j.jcrc.2011.10.010

31. Azoulay E, Adrie C, De Lassence A, Pochard F, Moreau D, Thiery G, et al. Determinants of postintensive care unit mortality: a prospective multicenter study. Crit Care Med. 2003;31(2):428-32. doi:10.1097/ 01.CCM.0000048622.01013.88.

32. Daly K, Beale R, Chang RW. Reduction in mortality after inappropriate early discharge from intensive care unit: logistic regression triage model. BMJ. 2001;322(7297):1274-6.

33. Smith L, Orts CM, O'Neil I, Batchelor AM, Gascoigne AD, Baudouin SV. TISS and mortality after discharge from intensive care. Intensive Care Med. 1999;25(10):1061-5

34. Ouanes I, Schwebel C, Francais A, Bruel C, Philippart F, Vesin A, et al. A model to predict short-term death or readmission after intensive care unit discharge. J Crit Care. 2012;27(4):422 e1-9. doi:10.1016/j.jcrc.2011.08.003.

\section{Submit your next manuscript to BioMed Central and take full advantage of:}

- Convenient online submission

- Thorough peer review

- No space constraints or color figure charges

- Immediate publication on acceptance

- Inclusion in PubMed, CAS, Scopus and Google Scholar

- Research which is freely available for redistribution 